\title{
Fiber Laser Welding Properties of Copper Materials for Secondary Batteries
}

\author{
Young-Tae YOU, Jin-Woo KIM* \\ Department of Mechanical System Engineering, Chosun University, 303, Pilmun-daero, Dong-gu, Gwangju 61452, Korea \\ crossref http://dx.doi.org/10.5755/j01.ms.23.4.16316
}

Received 30 September 2016; accepted 18 March 2017

\begin{abstract}
Secondary battery is composed of four main elements: cathodes, anodes, membranes and electrolyte. The cathodes and the anodes are connected to the poles that allow input and output of the current generated while the battery is being charged or discharged. In this study laser welding is conducted for 40 sheets of pure copper material with thickness of $38 \mu \mathrm{m}$, which are used in currently manufactured lithium-ion batteries, using pulse-wave fiber laser to compare welded joint to standard bolt joint and to determine optimum process parameters. The parameters, which has significant impact on penetration of the pulse waveform laser to the overlapped thin sheets, is the peak power while the size of the weld zone is mainly affected by the pulse irradiation time and the focal position. It is confirmed that overlapping rate is affected by the pulse repetition rate rather than by the pulse irradiation time. At the cross-section of the weld zone, even with the increased peak power, the width of the front bead weld size does not change significantly, but the crosssectional area becomes larger. This is because the energy density per pulse increases as the peak power increases. Keywords: ultra-thin copper, pure copper, lap-joint welding, fiber laser, lithium secondary battery.
\end{abstract}

\section{INTRODUCTION}

In the modern automobile industry, there is a growing interest in developing eco-friendly vehicles. Eco-friendly cars are manufactured for reducing the use of fossil fuels and mitigating green gas emissions, in addition to powersaving engines and high-capacity batteries, which are their core competitive features. The key for batteries development is high capacity and light weight.

Today's secondary battery is composed of four main elements: cathodes, anodes, membranes and electrolyte. The cathodes and the anodes are connected to the poles that allow input and output of the current generated while the battery is being charged or discharged. Fig. 1 shows the inside of the lithium secondary battery $[1-8]$.

As shown in Fig. 1, the cathode and the anode are connected to the pole using mainly bolt joint. Bolts are tightened with nuts that adversely affects the weight, which is a key important for developing cells with increased energy density. For high-density energy sources, laser welding offers advantages of melting and solidification within a short period of time, along with little thermal deformation. Owing to larger aspect ratio, greater penetration depth and smaller Heat Affected Zone (HAZ), laser welding offers many advantages. Compared to common welding, it is more sparing to the base material in terms of metallographic and mechanical properties, having thus excellent weldability [9-14].

In this study, laser welding is conducted for 40 sheets of pure copper material with thickness of $38 \mu \mathrm{m}$, which are used in currently manufactured lithium-ion batteries, using pulse-wave fiber laser to compare welded joint to standard bolt joint and to determine optimum process parameters.

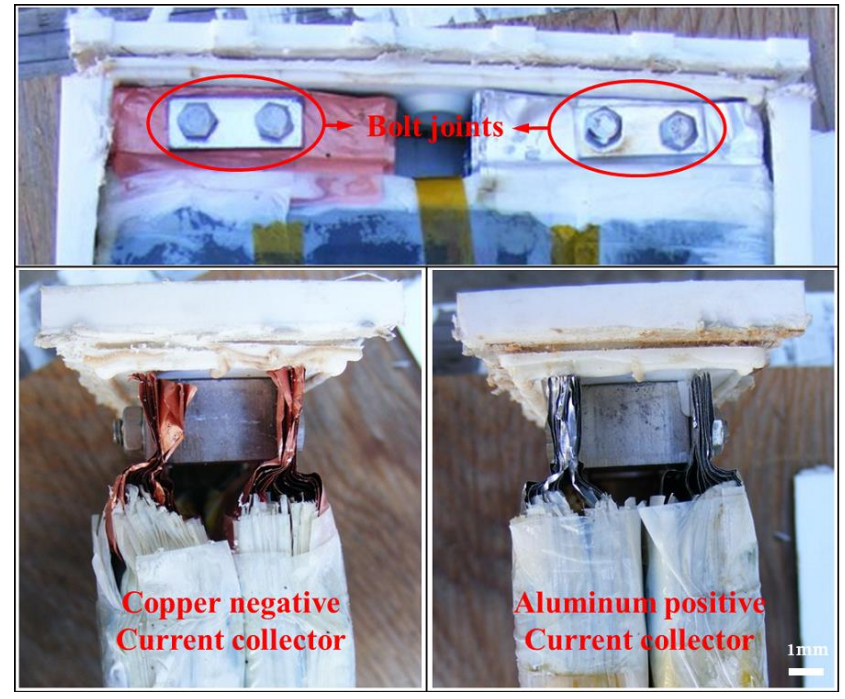

Fig. 1. Bolt joints of lithium secondary batteries

\section{EXPERIMENTS}

\subsection{Experimental setup}

The fiber laser used in this study is a dual mode laser (YLS-600/6000-QCW-AC), which can generate continuous and pulse waves with wave length of $1.07 \mu \mathrm{m}$; the maximum average power is $600 \mathrm{~W}$, and the maximum peak power is $6 \mathrm{~kW}$. The laser beam is transmitted through the optical fiber with diameter of $50 \mu \mathrm{m}$ and focal diameter $78 \mu \mathrm{m}$. The optical system of the laser welding head has the focal distance of $\mathrm{f}=250 \mathrm{~mm}$. The Beam Parameter Product (BPP) is $2.0 \mathrm{~mm} \cdot \mathrm{mrad}$. The equipment used in this study is shown in Fig. 2.

\footnotetext{
* Corresponding author. Tel.: +82-62-230-7014; fax: +82-62-230-7171.

E-mail address: jinu763@chosun.ac.kr(J. Kim)
} 


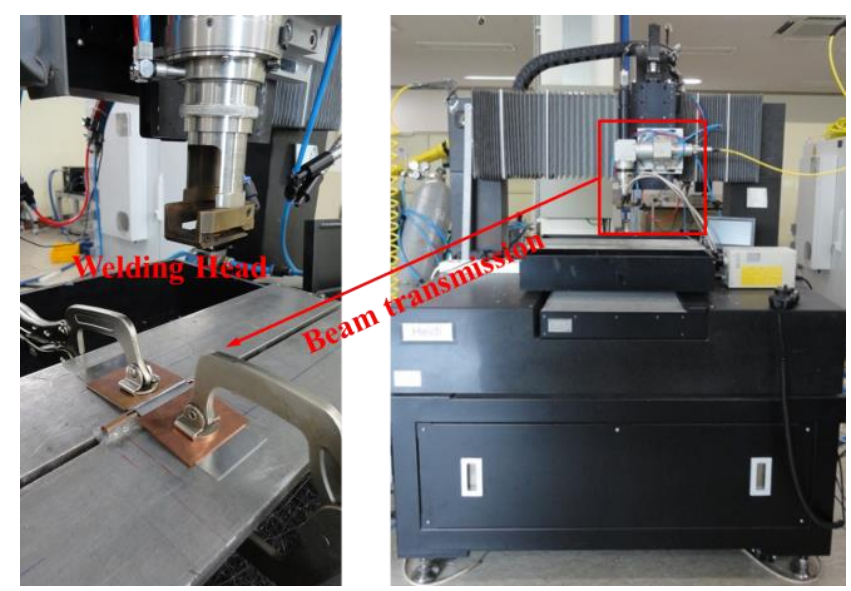

Fig. 2. Fiber laser and lap welding experiment equipment

\subsection{Experimental methods and specimens}

In this study, specimens are made of pure copper material shaped into a size of $150 \mathrm{~mm} \times 50 \mathrm{~mm} \times 0.038 \mathrm{~mm}$ to determine optimum process for laser welding. Forty ultra-thin sheets $(38 \mu \mathrm{m})$ of copper with purity of $99.9 \%$ or higher are overlapped for welding. The chemical composition of the specimen is shown in Table 1.

Table 1. Chemical composition of pure copper (wt.\%)

\begin{tabular}{|c|c|c|c|c|c|}
\hline $\mathrm{Ag}$ & $\mathrm{Bi}$ & $\mathrm{Pb}$ & $\mathrm{O}$ & Other & $\mathrm{Cu}$ \\
\hline 0.05 & 0.001 & 0.005 & 0.04 & 0.03 & Bal. \\
\hline
\end{tabular}

In order to study welding characteristics according to focal position of the laser beam, this study conduct laser welding with different laser peak power $(5$ and $6 \mathrm{~kW}$ ), focal position $(\mathrm{F}=-3,0,+3)$, pulse irradiation time and pulse repetition rate of the laser beam, with laser beam feed rate fixed to $0.5 \mathrm{~m} / \mathrm{min}$.

Focal position of specimen surface is $f=0$. Because of design features of the equipment, the pulse irradiation time is predetermined when the pulse repetition rate is fixed and once it is determined, the pulse repetition rate can be determined. The corresponding relations are shown in Eq. 1 and Eq. 2. 40 specimen sheet was checked penetration-welded at the fixed pulse irradiation time (pulse repetition rate) as $4 \mathrm{~ms}(25 \mathrm{~Hz}), 6 \mathrm{~ms}(16 \mathrm{~Hz}), 8 \mathrm{~ms}$ $(12 \mathrm{~Hz})$ and $10 \mathrm{~ms}(10 \mathrm{~Hz})$, while varying the peak power.

The obtained cross-sections of the weld are subject to hot-mounting on the mounting press for texture analysis. The weld sections, which are made rough by cutting, are polished to facilitate texture analysis. The polished specimens are etched with a chemical solution of $\mathrm{FeCl}_{3}+\mathrm{HCl}+\mathrm{Glycerin}+\mathrm{H}_{2} \mathrm{O}$. The boundary surface of the etched weld bead was observed using optical microscope (Olympus: GX-51). In short, 40 thin sheets were overlapped to weld them together, cut the welded specimen, and measure the penetration depth and width of the weld using optical microscope.

The specimen of 40 thin sheet was firmly fixed using the jig attached to the workbench, in order to prevent deformation caused by thermal expansion during welding.
For each welding condition, tensile test was conducted to measure the mechanical properties of the weld, using a tensile tester (Hounsfield universal testing machine) with tensile specimens fixed at the right angle to the tensile load direction. Pulse time and pulsed on time are defined as:

$$
\text { Pulse time }(T)=\frac{1}{\operatorname{Repetitionrate}(f)} \text {; }
$$

Pulsed on time $(t)=\operatorname{Pulsetime}(t) \times \operatorname{Duty} \operatorname{ratio}(D)$.

\section{RESULTS AND DISCUSSION}

\subsection{Laser welding characteristics}

In order to analyze the overlap rate and the front bead width, 40 thin copper sheets with the thickness of $38 \mu \mathrm{m}$ were welded using a fiber laser and examined the weld using an optical microscope. The images are shown in Fig. 3. The image in Fig. 3 a shows that 40 specimen sheets are not evenly penetrated and welded when the focal position is $\mathrm{f}=0$, and the pulse repetition rate and irradiation time are $10 \mathrm{~ms}$ and $10 \mathrm{~Hz}$ respectively. The bead widths observed for different focal positions, with fixed pulse repetition rate and irradiation time, are shown in Fig. 4.

As illustrated, when the frequency is reduced with the peak power and the laser beam feed rate being fixed, the pulse irradiation time increases, and the front bead width of the weld per unit pulse increases accordingly. It is determined that if the pulse irradiation time increases at constant peak power, the energy per pulse increases and the interaction time between the laser beam and the specimen becomes longer, resulting in the increase of the weld width. In addition, it is shown that the bead width varies with focal position.

If the focal position when the focal plane of the laser beam is above the specimen surface is $f=0$, at the focal position $f=+3$, thermoelectric beads with low energy density are formed on the specimen surface to spread thermal energy throughout the surface by the laser beam, thus increasing the weld width.

At the focal position $\mathrm{f}=0$ the energy density becomes higher on the specimen surface and the heat builds up rapidly, penetrating the specimen more deeply. As a result, though the bead width smaller than when the focal position is $\mathrm{f}=+3$.

Though it may seem that the overlap rate would increase as the pulse irradiation time increases and thus the weld front bead width increases when the pulse repetition rate is reduced under the same conditions, it actually decreases as the laser beam irradiation count is reduced when the pulse repetition rate is reduced.

The measured overlap rate is shown in Fig. 5. As illustrated, the overlap rate depends on the pulse repetition rate rather than by the pulse irradiation time. The overlap rate is calculated according to Eq. 3. In Eq. 3, $\mathrm{S}^{\prime}$ represents the distance from the origin without overlap and $S$ represents the moving distance of the focus size depending on the feed rate. 

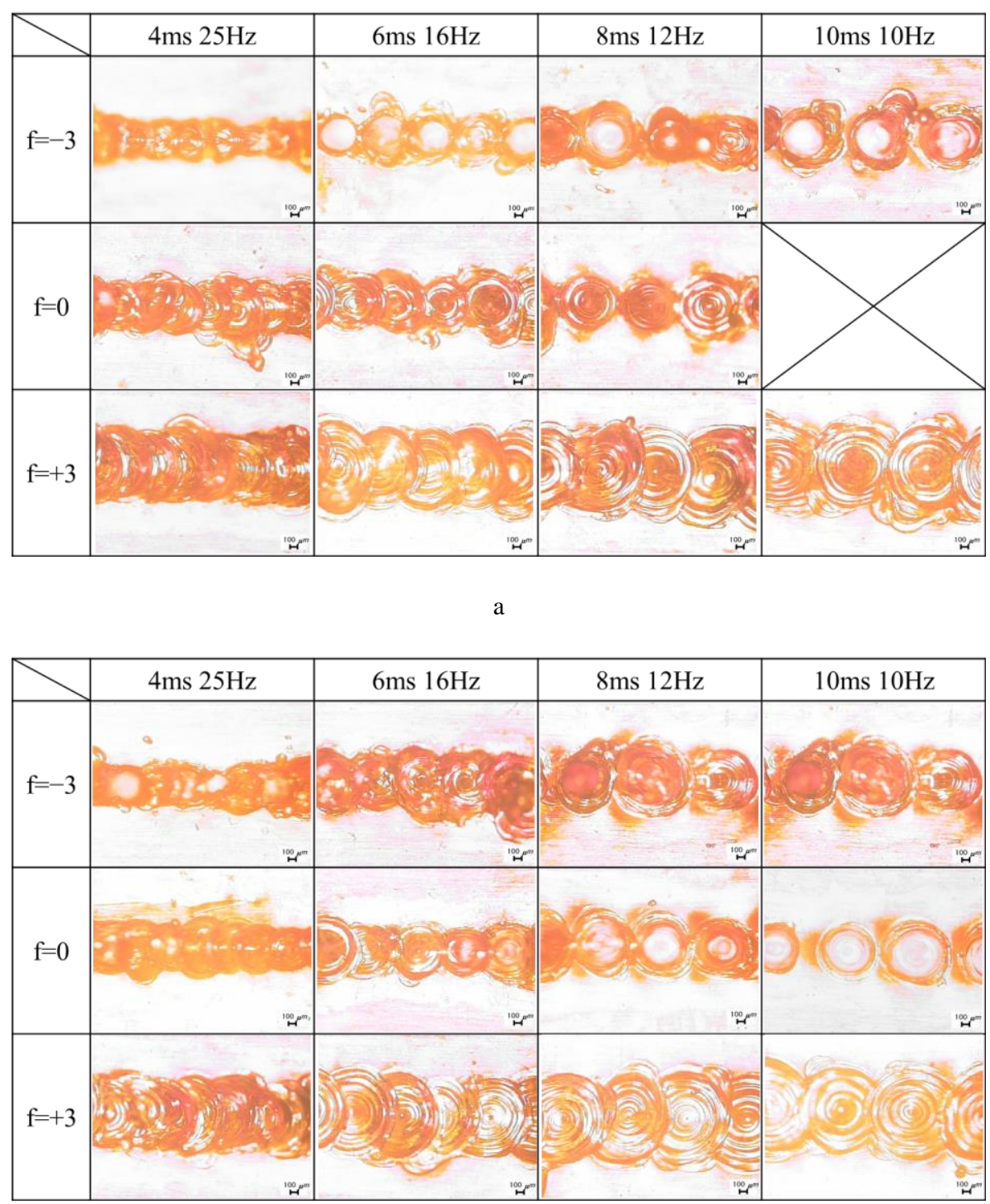

b

Fig. 3. Overlap variations according to process parameters; peak power: $\mathrm{a}-5 \mathrm{~kW}$; $\mathrm{b}-6 \mathrm{~kW}$

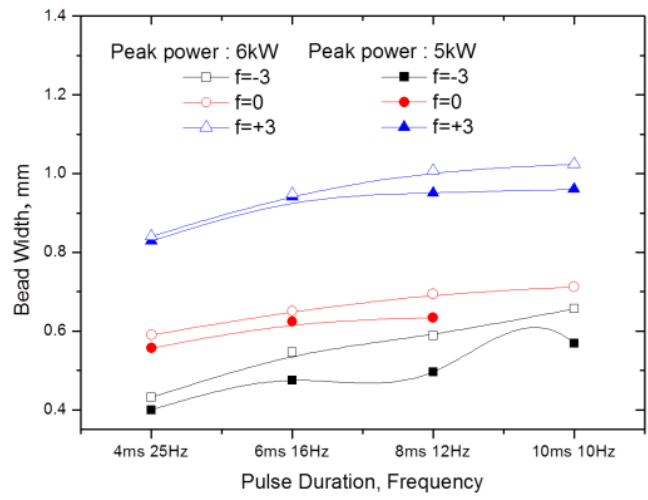

Fig. 4. Variations of front bead width according to process parameters

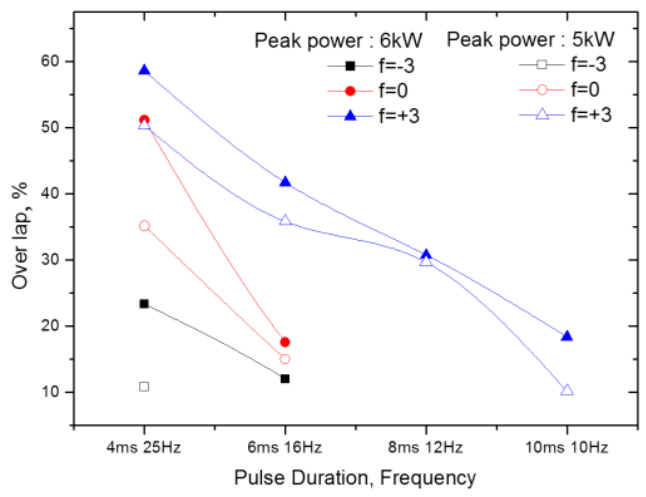

Fig. 5. Variations of overlap according to pulse duration and frequency 


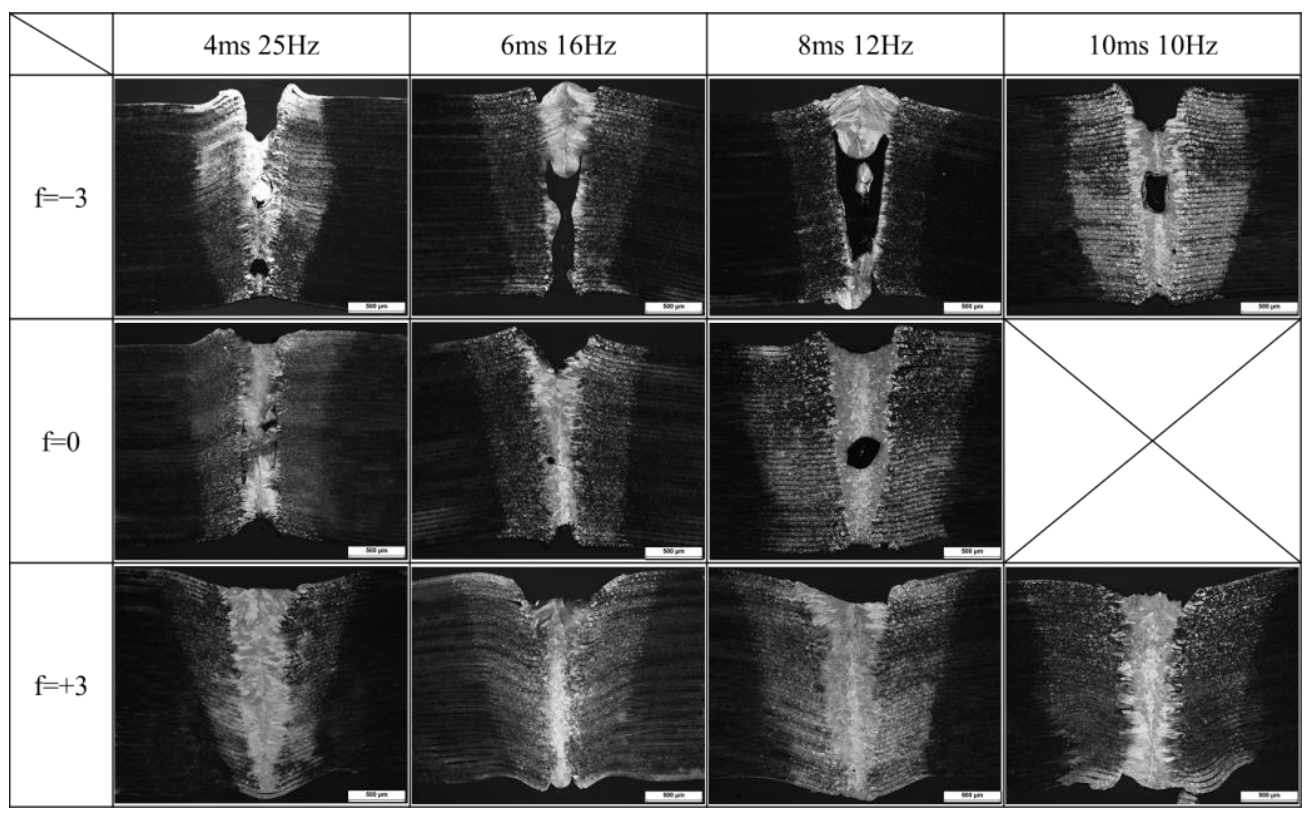

a

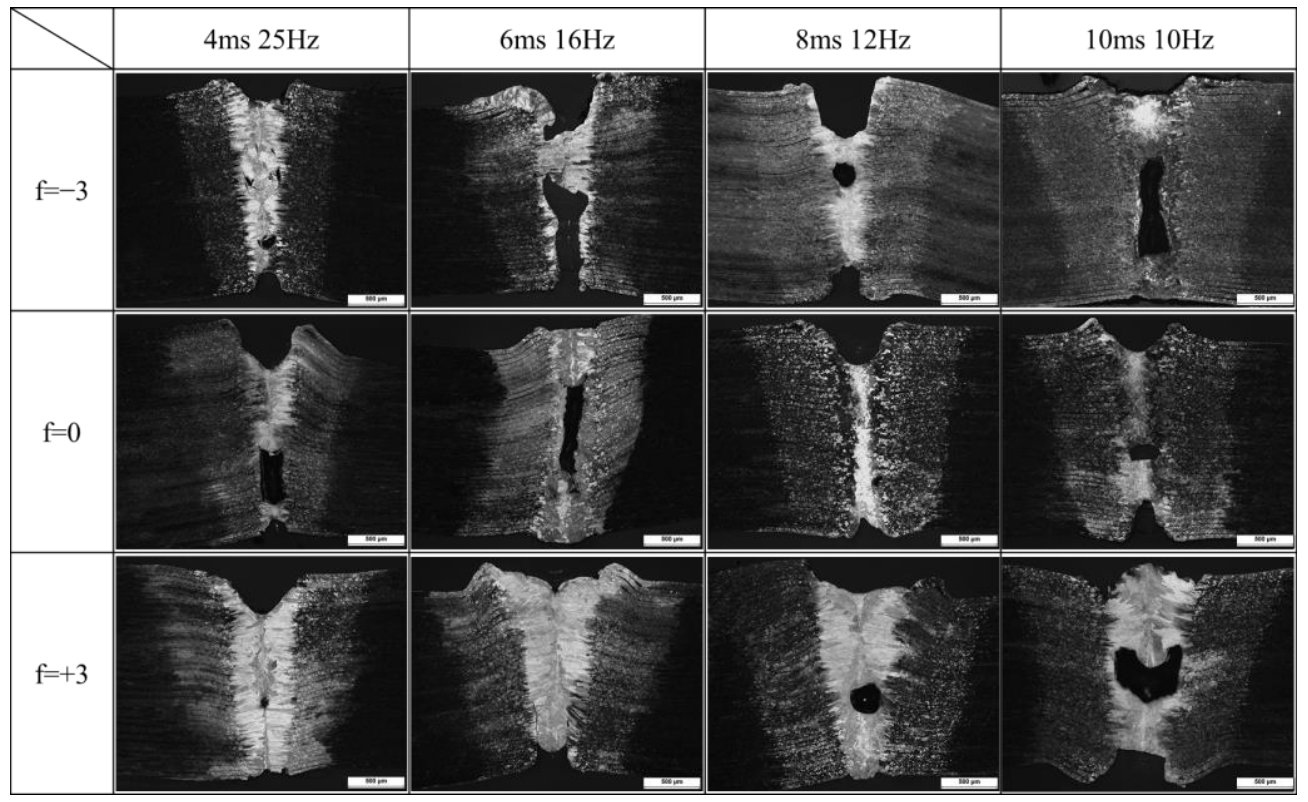

$\mathrm{b}$

Fig. 6. Welding cross-sectional area depending on welding parameters; peak power: $\mathrm{a}-5 \mathrm{~kW} ; \mathrm{b}-6 \mathrm{~kW}$

$P_{\mathrm{ER}}=\left[1-\frac{S^{\prime}}{S}\right] \times 100$.

As shown in Fig. 4, when the peak power is increased at fixed pulse irradiation time and pulse repetition rate, the front weld bead width increases by about $0.01 \sim 0.1 \mathrm{~mm}$. When the pulse repetition rate is reduced while the peak power is fixed, it increases by about $0.1 \sim 0.3 \mathrm{~mm}$. When the focal position is increased with the peak power and the pulse repetition rate are fixed, it increases by about $0.1 \sim 0.5 \mathrm{~mm}$. Therefore, it is confirmed that the front bead width has more impact on the pulse irradiation time and the focal position than on the peak power. As mentioned before, this is because the increase rate of the front bead width is insignificant when the peak power is increased while the pulse repetition rate and the pulse irradiation time are fixed.

\subsection{Aspect ratio and heat input characteristics}

The experiments for each process parameter were conducted and then the cross-section of the weld was analyzed. The results are shown in Fig. 6. As illustrated, the weld cross-section demonstrates that even though with the increased peak power, the weld width of the front bead does not change significantly, but the cross-sectional area of the weld increases. This is because the energy density per pulse increases with the peak power.

Like this, when the peak power or the pulse irradiation time increases, the energy density per pulse increases as 
well. The reason why the energy density per pulse increases is that the energy remaining after making the key hole for welding 40 overlapped sheets goes to increase the cross-sectional area of the welded part.

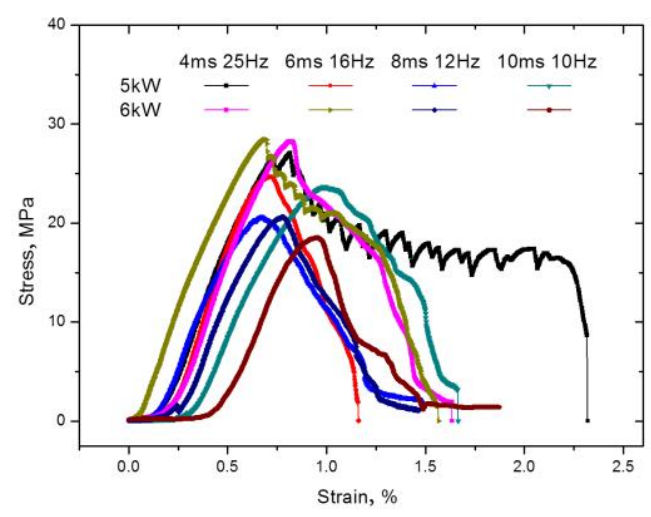

Fig. 7. Measured stress as a function of strain for laser weld (focal position $\mathrm{f}=-3$ )

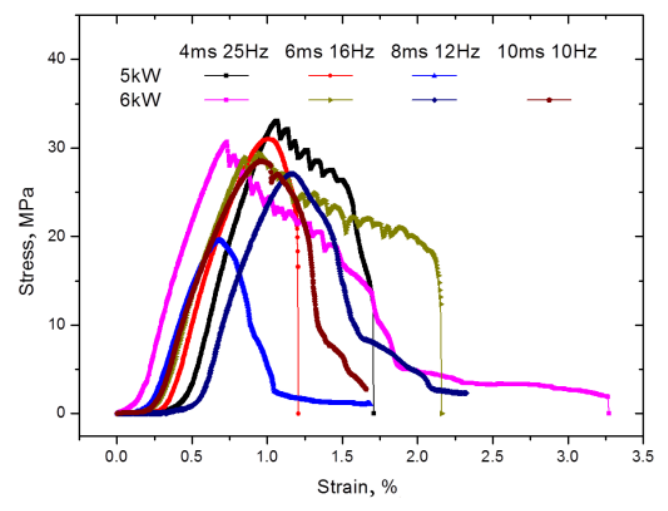

Fig. 8. Measured stress as a function of strain for laser weld (focal position $\mathrm{f}=0$ )

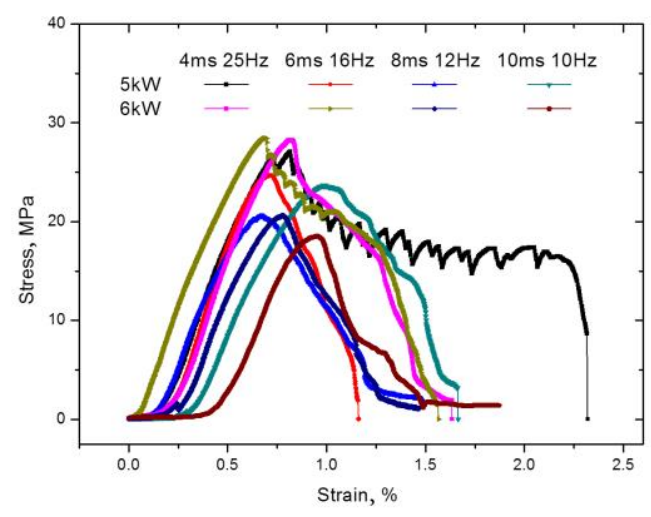

Fig. 9. Measured stress as a function of strain for laser weld (focal position $\mathrm{f}=-3$ )

The specimen made of 40 thin copper sheets overlapped and welded according to No. 13B of the tensile test specimens for metal materials according to the Korea Industrial Standard was prepared, and conducted wirecutting to ensure minimal thermal impact and precision.

The results of the tensile strength test according to the pulse irradiation time and pulse repetition rate when the focal position is $f=-3$ are shown in Fig. 7 . The maximum tensile strength at the focal position $f=-3$ is observed when the peak power is $6 \mathrm{~kW}$ and the pulse repetition rate and the pulse irradiation time are $6 \mathrm{~ms}$ and $16 \mathrm{~Hz}$ respectively.

When the focal position $\mathrm{f}=-3$, the laser beam accesses the focal plane at a position lower than the surface of the specimen, causing bubbling. These bubbles cannot be released, but are trapped into the specimen as the cooling rate of the melting is very fast, resulting in undercut. As the laser beam, which passes the focusing lens, is irradiated on the specimen while being converged into a direction below the surface of the specimen, the excessive heat is generated, and some chemical composition of the specimen is vaporized to create bubbles on the welded surface that lowers the tensile strength. As copper has very high thermal and electrical conductivity, the heat from the welded section is lost very fast. As the melting pool is solidified, bubbles are trapped in the weld, resulting in defects and reducing the tensile strength. If the focal position is $f=0$, which is the surface of the specimen, the key hole cannot be formed property due to high peak power, that results in under-fill. On the other hand, when the focal position is $f=+3$, a relatively less bubbles are created, and the tensile strength is higher. At $\mathrm{f}=+3$, meaning that the focal position is above the surface of the specimen, the center of the transverse strength distribution of the laser beam originating from the laser beam passing through the focal plane shows Gaussian distribution. This increases the temperature of the perimeter of the weld line and thus delays solidification. As a result, the flow of the fluid pool of the key hole becomes free, removing defects from the interior of the weld zone and increasing the tensile strength.

\section{CONCLUSION}

This study is dedicated to welding of 40 overlapped $38 \mu \mathrm{m}$ thin sheets of the pure copper using a pulsewaveform fiber laser. During the overlap welding, process parameters was changed according to the focal positions and analyze the energy density per pulse, the front/rear bead width ratio, the heat input, the metallurgical properties, and the mechanical tensile strength were analyzed. This study concludes as follows:

1. The parameters, which has significant impact on penetration of the pulse waveform laser to the overlapped thin sheets, is the peak power while the size of the weld zone is mainly affected by the pulse irradiation time and the focal position. It is confirmed that overlapping rate is affected by the pulse repetition rate rather than by the pulse irradiation time.

2. At the cross-section of the weld zone, even with the increased peak power, the width of the front bead weld size does not change significantly, but the crosssectional area becomes larger. This is because the energy density per pulse increases as the peak power increases.

3. According to the tensile strength analysis, the tensile strength of 40 overlapped $38 \mu \mathrm{m}$ thin sheets reaches the maximum of $69.8 \mathrm{MPa}$ when the focal position is $\mathrm{f}=+3$, the peak output is $5 \mathrm{~kW}$, the pulse irradiation time and the pulse repetition rate are $4 \mathrm{~ms}$ and $25 \mathrm{~Hz}$ 
respectively. These figures are about 2.1 times and 2.5 times higher than those for the focal positions $f=0$ and $\mathrm{f}=-3$.

4. Though it is possible to replace the conventional the bolt fastening with the laser weld, further research is needed to examine the possibility of removing weld defects during laser welding.

\section{Acknowledgments}

This study was supported by the research fund from Chosun University (2017).

\section{REFERENCES}

1. Benyounis, K.Y., Olabi, A.G., Hashmi, M.S.J. Optimizing the Laser-Welded Butt Joints of Medium Carbon Steel Using RSM Journal of Materials Processing Technology 164 2005: pp. 986-989.

https://doi.org/10.1016/j.jmatprotec.2005.02.067

2. Wang, X.Y., Liu, Z., Chong, P.H. Effect of Overlaps on Phase Composition and Crystalline Orientation of LaserMelted Surfaces of 321 Austenitic Stainless Steel Thin Solid Films 453 2004: pp. 72-75. https://doi.org/10.1016/j.tsf.2003.11.078

3. Yue, T.M., Yan, L.J., Chan, C.P. Stress Corrosion Cracking Behaviour of Nd:YAG Laser-Treated Aluminium Alloy 7075 Applied Surface Science 252 2006: pp. 5026-5034. https://doi.org/10.1016/j.apsusc.2005.07.052

4. Sun, Z., Kuo, M., Hashmi, M.S. Bridging the Joint Gap with Feed Laser Welding Journal of Materials Processing Technology 87 (1-3) 1999: pp. 213-222.

5. Khallaf, M.E., Ibrahim, M.A., El-Mahallawy, N.A., Taha, M.A. On Crack Susceptibility in the Submerged Arc Welding of Medium-Carbon Steel Plates Journal Materials Processing Technology 68 (1) 1997: pp. 43-49.
https://doi.org/10.1016/S0924-0136(96)02530-7

6. Hosking, F.M., Stephens, J.J., Rejent, J.A. Intermediate Temperature Joining of Dissimilar Metals Welding Journal 77 (4) 1997: pp. $127-136$.

7. Qian, M., Lippold, J.C. Phenomena in the Simulated Heataffected Zone of Alloy 718 after Multiple Postweld Heat Treatment Cycles Welding Journal 82 (6) 2003: pp. $145-150$.

8. Kusko, C.S., Dupont, J.N., Marder, A.R. The Influence of Microstructure on Fatigue Crack Propagation Behavior of Stainless Steel Welds Welding Journal 83 (1) 2004: pp. 6-15.

9. Kim, J.D., Kim, C.J., Chun, C.M. Repair Welding of Etched Tubular Components of Nuclear Power Plant by Nd:YAG Laser Journal Materials Processing Technology 114 (1) 2001: pp. $51-56$. https://doi.org/10.1016/S0924-0136(01)00566-0

10. Cam, G., Erim, S., Yeni, C., Kocak, M. Determination of Mechanical and Fracture Properties of Laser Beam Welded Steel Joints Welding Journal 78 (6) 1999: pp. 193-201.

11. Iamboliev, T., Katayama, S., Matsunawa, A. Interpretation of Phase Formation in Austenitic Stainless Steel Welds Welding Journal 82 2003: pp. 337-347.

12. Dupont, J.N., Banovic, S.W., Mard, A.R. Microstructural Evolution and Weldability of Dissimilar Welds between a Super Austenitic Stainless Steel and Nickel-Based Alloys Welding Journal 82 2003: pp. 125-135.

13. Ogborn, J.S., Olson D.L., Cieslak, M.J. Influence of Solidification on the Microstructural Evolution of Nickel Base Wled Metal Materials Science Engineering 203 (1-2) 1995: pp. 134-139.

14. Quan, Y., Chen, Z., Gong, X., Yu, Z. $\mathrm{CO}_{2}$ Laser Beam Welding of Dissimilar Magnesium-Based Alloys Materials Science Engineering 496 2008: pp. 45-51. https://doi.org/10.1016/j.msea.2008.04.065 